\title{
Social Features and Morbidity Patterns of Women with Obstetric Fistulae at an Obstetric Fistula Centre in a University Teaching Hospital in Jos, Nigeria
}

\author{
Aaron Ezekiel, C. Okafor Kingsley, J. M. Ijairi, Ayobami A. Mufutau, \\ Steve T. Olaniyan, and Idoko Lucy
}

\section{ABSTRACT}

Obstetric fistulae are largely preventable surgical conditions. Literature has shown that it is common among the low income, less privileged and marginalized members of the community. It affects mainly the poor, young, illiterate girls, and women in the remote rural areas of the world, where access to emergency obstetric care, family planning services and skilled birth attendants are unavailable. And when available are poorly utilized due to cost, distance, and other challenges. This study seeks to identify the social features and morbidity characteristics of obstetric fistulae in women at the fistula center in Bingham University Teaching Hospital, Jos, Plateau State, Nigeria. This was a descriptive study done in 2019 among all the patients who attended the obstetric fistula Centre at Bingham University Teaching Hospital. An Interviewer-administered structured questionnaire was used, and it looked at social and health aspects of obstetric fistulae in all 49 patients at the center. Data was analyzed using a computer software; Statistical Package for the Social Science (SPSS) version 20.0. Most of patients had some form of financial support especially from family members, husbands, parents, and friends. Most of the women had their relationships affected. Majority were separated, and relationships strained and had lost financial support from their spouses. Sexual Intercourse was adversely affected. On surgical outcome, $16 \%$ became completely dry and leaking had ceased, a third $(36.7 \%)$ was still leaking urine after the surgery. Almost all the women have had no childbirth after the repair. Women had mental health issues like depression, anxiety, tension headache, fatigue, and suicidal ideation. Participants also had gynaecological morbidities like vulval dermatitis, irregular menstrual flow, abnormal vaginal discharge, and dysuria. These women also had lower abdominal pains, loss of weight, backache, and foot drop. Majority of the children did not survive after the pregnancy that led to the obstetric fistula. Women should seek financial support from family members to avoid delays in seeking help during pregnancy. Communities are encouraged to continue to give moral, emotional, financial, and social support to fistula patients. Healthcare workers should take advantage of the fact that most women attended ANC to educate and enlighten pregnant women on causes, risk factors, social and health consequences of obstetric fistulae. Government should initiate poverty alleviation activities and help reduce out of pocket expenses for healthcare via health insurance.

Keywords: Obstetric fistula, Social Features, Morbidity features, Women.

\section{INTRODUCTION}

World Health Organization (WHO) describes an Obstetric Fistula (OF) as an "abnormal opening between a woman's vagina and bladder and/or rectum through which her urine and/or faces continually leak [1], [2]. Prolonged obstructed labor is a leading cause of OF in low socio-economic regions like South Asia, and Sub-Saharan Africa. It is estimated that fistulae occur in one to three of every 1,000 deliveries [3], [4]. According to WHO, an estimated 50,000 to 100,000 women
Submitted : April 30, 2021

Published : July 11, 2021

ISSN: $2593-8339$

DOI: $10.24018 /$ ejmed.2021.3.4.844

Aaron Ezekiel

Department of Community Medicine \& PHC, Bingham University, Karu, Nasarawa State, Nigeria.

C. Okafor Kingsley*

Department of Community Medicine \& PHC, Bingham University, Karu, Nasarawa State, Nigeria.

(e-mail: drokaforkingsley@gmail.com) J. M. Ijairi

Department of Community Medicine \& PHC, Bingham University, Karu, Nasarawa State, Nigeria.

Ayobami A. Mufutau

Department of Community Medicine \& PHC, Bingham University, Karu, Nasarawa State, Nigeria.

Steve T. Olaniyan

Department of Community Medicine \&

PHC, Bingham University, Karu, Nasarawa State, Nigeria.

Idoko Lucy

Department of Community Medicine \& PHC, Bingham University, Karu, Nasarawa State, Nigeria.

*Corresponding Author worldwide develop obstetric fistulae annually [5]. The United Nations Population Fund (UNFPA) also states that more than 2 million women in Asia and Sub-Saharan Africa are living with an untreated obstetric fistula and the resulting urinary and/or rectal incontinence. It is estimated that Nigeria accounts for about $40 \%$ of the worldwide fistulae prevalence [3], [6].

For women with unattended obstructed labor, the labor produces contractions that push the baby's head against the mother's pelvic bone. The soft tissues between the baby's 
head and the pelvic bone are compressed and do not receive adequate blood flow [7], [8]. The lack of blood flow causes this delicate tissue to die and where it dies holes are created between the laboring mother's bladder/urethra and vagina and/or between the rectum and vagina. This is what produces incontinence in a fistula patient. Dripping urine wets clothing of the victims and also leads to excoriation of the already damaged vulva and vagina in addition to emitting a foul smell [9], [10].

Beyond the obvious physical and anatomic burdens of the urinary and fecal incontinence, the burden of disease encompasses many other physical, social, and psychological consequences. The victims could become social outcasts, get divorced and rejected by their families. Some of them travel long distances in search of treatment [11], [12]. There are underlying social causes of obstetric fistula which include poverty, illiteracy, early marriage and childbirth, inadequate family planning, low status of women in the community, harmful traditional practices such as female genital mutilation and other factors affecting women in the community [3], [13].

Obstetric fistula is largely a preventable condition, but literature has shown that it is common among the low income, less privileged and marginalized members of the community. It affects the poor, young, illiterate girls and women in the remote rural areas of the world, where access to emergency obstetric care, family planning services and skilled birth attendants are unavailable and where available poorly utilized due to cost, distance and other challenges [14]-[16].

To tackle this public health burden, equipped OF centres and good obstetric care facilities covering emergency obstetric and neonatal care, family planning, early catheterization, delivery service and husband partnership, rehabilitation and must be in place [3]. Besides ECWAEvangel Vesico-Vaginal Fistula Center, Jos, Plateau state and Family Life Center Fistula Hospital, Mbribit Itam, Uyo, Akwa-Ibom state; there are currently more than 12 fistula centers spread across Nigeria (National Obstetric Fistula Centre, Abakaliki, National Obstetric Fistula Center, Babbar Ruga in Katsina State, National Obstetric Fistula Center, Ningi, in Bauchi State, Gesse Fistula Center in Birnin kebbi, Faridat Yakubu General Hospital Zamfara state, Laure Madaki Fistula Center Kano state, Maryam Abatcha Women and Children's Hospital (MAWCH) in Sokoto State, Ogoja Fistula Center in Cross River State, Sobi Specialist Hospital in Kwara State, The University College Hospital at the University of Ibadan in Oyo State, Jahun VVF Center, and Adeoyo General Hospital at Ibadan, Oyo State) [17]. Most of these centers are in the northern region of Nigeria which holds a higher prevalence.

The social consequences include divorce by husbands, and abandonment and ostracism by affected women's families and community. This is due to the uncontrollable leakage of urine and/or faeces and the accompanying smell. Fistula also leaves women with few opportunities to earn a living, worsening their poverty [18], [19].

Obstetric Fistula is a devastating and distressing chronic condition with dire consequences on the health of the woman. Obstetric fistula has both health and social penalties. Women who experience this preventable condition suffer constant urinary and/or faecal incontinence which leads to social isolation, skin infections, kidney disorders and even death if left untreated [20], [21].

Health complications due to obstetric fistula include the following: Vulva dermatitis: Chronic contact of skin (labia, perineum, and groin) with urine and stool leads to irritation and excoriation and sometimes ulceration of the skin. A study done in Kano found that vulva dermatitis occurred in $31 \%$ of the patients [22]. In a study in Benin City, $20 \%$ of fistula patients had Vulval dermatitis [23].

In foot drop, women with obstetric fistulae usually suffer from walking difficulties after the delivery, they have leg pain and loss of function in the ankle and knee joints thereby inhibiting movement. Foot drop and walking difficulties in some of these women signify an extensive injury and peroneal nerve damage. A study done in Kano showed that $23 \%$ of the fistula patients had foot drop [22]. In Kenyatta National Hospital Kenya, 31.4\% of OF patients had foot drop [24].

Amenorrhea is also a sequela of obstetric fistula which makes it difficult for the women to get pregnant despite their young age. The significance of this will be better appreciated when one considers that bearing children is highly treasured in this society. These women often have low self-esteem and have concerns even after the surgical repair. A study in Kano showed that $17.5 \%$ of fistulae patients had amenorrhea [22]. In a study at Benin City, amenorrhea was found in $5 \%$ of fistulae patients [23] and 51\% in Osun State [25].

Infertility is a real health challenge faced by women with obstetric fistulae. Women who have had fistulae find it difficult to conceive because of multifactorial causes which may be psychological, lack of sexual drive or due to stenosis of the vagina. A study conducted in Benin City showed that $5 \%$ of the women had infertility [23] and $21.4 \%$ in Kenyatta National Hospital, Kenya [24]. Dyspareunia was found to be $47.1 \%$ in a study conducted in Bingham University Teaching Hospital Jos [26].

Urinary tract infections occur in these women. Many of the OF patients live with OF for several years and are at risk of having recurrent Urinary Tract Iinfections (UTI). In general, fistula treatment requires prolonged period of hospitalization and urinary catheterization which may also be a contributory factor. Fistula patients are often malnourished, with low immunity and have low socioeconomic status. Low educational level has also been linked to the development of recurrent UTI [27]. These women often complain of burning sensation during urination and lower abdominal pain. Recurrent Urinary Tract Infections were found to be $9.2 \%$ in a study in Kano [22] and $10 \%$ in Benin City [23]. The overall prevalence of UTI amongst fistula patients in Ethiopia is $58.1 \%$ [27].

Mental health conditions like depression occurs frequently in women with obstetric fistula. Symptoms of depression were more prevalent among rural residents' divorcees than currently married and among housewives than employed. Sexual intercourse is often affected, thus straining marital relationships and increasing rates of divorce [28]. Depression was found to be $33 \%$ in Kano [22]. Two studies conducted in Ethiopia show that $97.0 \%$ [28] and $92.3 \%$ [29] of OF patients had depressive symptoms, and $54.2 \%$ have had suicidal ideation.

Beyond the serious medical consequences, many girls and women are socially stigmatized and ridiculed, they become 
so ashamed of their condition that they isolate themselves from their communities, lose social support, separate, or divorce their spouses and distance themselves from families. Some have malnutrition and worsening poverty leading to suffering. Often these women give birth to stillborn babies leaving them childless. Moreover, these women may be left with few, if any, opportunities to earn a living, and be forced to rely on others to survive. The costs of seeking treatment can also result in severe economic hardship [30].

Obstetric fistula impacts on marital status. It is a common event that fistula-affected women face divorce or separation as they fail to satisfy their husband's sexual needs, fail to bear children, or even smell of urine. As the women become incapable of performing the family roles expected of them, they become neglected and abandoned [30]. Minority of women that are married might not have sexual intercourse with their husbands after fistula formation. Some partners who were happy prior to fistula development, eventually fail to share the bed and do not have sex. A few of the women who were single at the time of the fistula may have their partners refusing to marry them [31]. According to an Ethiopian study of 78 previously married women with fistula repairs, majority (59) of them were divorced while the remainder (19) were abandoned by their husbands [32]. In Zambia, a study on women with VVF receiving care at Monze Hospital reported that three-quarters of women with fistula were married, $15.1 \%$ divorced, $7.5 \%$ single, and $1.7 \%$ widowed. Among the 45 women who were no longer living with their husbands, $31(67 \%)$ stated that this was due to their fistula. ${ }^{33}$ In Niger, fistula accounts for $63.3 \%$ of all divorces [34]. In Nigeria, a study of 31 fistula patients reported that the divorce rate, even after repair, was $55 \%$ and $87 \%$ of these women had a stillbirth [35]. In Guinea, women who developed VVF often suffered stigma, abandonment, loss of self-esteem, and varying degrees of social isolation. They were considered perpetually unclean as sometimes they were even excluded from food preparation, social events, and prayer ceremonies [36]. In Nigeria, where childbearing is central to women's status, the loss of both a child and the role of motherhood are devastating. Women with VVF therefore face social isolation. Social isolation reinforces the woman's belief that she is to blame and has brought shame on her family [35]

Stigmatization and isolation are common social features of OF. Majority of the women with fistula tend to isolate themselves from their communities. They remain in their homes as much as possible, stop making social visits, and no longer attend public events such as funerals, celebrations, and meetings. They feel a strong sense of shame about their condition and do not want to people to perceive the bad smell of urine or faeces when it occurs [31]. Studies done in Bangladesh, Guinea, Niger, Nigeria, and Uganda have revealed that significantly larger proportions of women were living with parents at admission than before the fistula developed. Overall, very few women said they lived alone before the fistula, although the proportion increased significantly by the time of admission and declined significantly by follow-up. Over one-quarter of women $(26.7 \%)$ reported that they were divorced at admission. Rates ranged from $21.1 \%$ in Nigeria to $32.9 \%$ in Guinea. Nearly, all women $(94.8 \%)$ said that fistula contributed to their divorce
[30]. Greater proportions of women from Bangladesh and Guinea, who were the oldest women in this cohort, were widowed [31]. The psychological or mental disturbance suffered by women with OF may be due to loss of dignity, lack of support, lack of power to seek care, loss of hope, fear of future life, and feelings of dependency [30]. A study in Nakuru, Kenya showed that $97.2 \%$ of affected women felt humiliated and $95.4 \%$ showed despair which they termed as the most difficult situation to bear [37].

Economic instability is another consequence of OF. Many women with OF lose their sources of income (if they had any) as they cannot get involved in gainful employment or activities that need strict hygiene. Some $\mathrm{t}$ lose business because of the incontinence and might be self-employed in petty trading where they earn too little income. In this way, fistula has challenged and contributed to poor status of women's health in developing countries [38]. In a studies done in Bangladesh, Guinea, Niger, Nigeria and Uganda a large majority of women $(87.7 \%$ ) said they could easily or somewhat easily meet their basic needs before fistula; this dropped to $78.5 \%$ at admission. Women who had lived with fistula for over a year were more likely to say that their condition interfered with their ability to work and earn money [30].

Women with $\mathrm{OF}$ are prone to a poor hygiene. They require strict adherence to hygienic practices like washing their clothes regularly and taking baths frequently [38]. Other coping mechanisms to manage odour and leaking of urine include changing clothes frequently, using perfumes and lotions, and wearing pads [39]. They tend to leak urine and are thus prone to infections of different types [30]. This maintenance of hygiene is costly. Generally, living with fistula interferes with women's daily lives, including the ability to attend community gatherings (85.3\%), having sexual relations $(85.2 \%)$, attending religious gatherings $(83.6 \%)$, earning money $(80.0 \%)$, gaining work $(72.1 \%)$, and eating with others $(68.7 \%)$ [30].

Family members of women affected by OF most likely suffer from stress and worry as a consequence of the fistula. They could be worried that the woman would be unable to get married, finish school, or to fend for herself. They may feel badly about the treatment of the women by the community and may be powerless to help them. Families of women with fistula face added expenses in the daily management of the woman's condition, such as costs for extra clothes and soap, and in efforts to seek treatment to repair the fistula. Treatment expenses incurred by families may include surgical repair and related expenses such as transport and lodging costs for the person accompanying the woman to the hospital, and food and other necessities while at the hospital, as well as payments to traditional healers [31]. In addition to these direct expenses of care and treatment, families can also be affected by the loss of the woman's contribution to work in the home, on the farm, or in earning income from other employment [38].

Some in-depth studies serve to support the widely held belief that the true number of women living with untreated fistula and suffering the consequent pain and degradation may have been underestimated, suggesting that there may be between 100000 and one million women living with fistula in Nigeria alone and over 70000 in Bangladesh [40], [41]. In 
Ethiopia it is estimated that 9000 women annually develop a fistula, of which only 1200 are treated [42]. Studies from Ethiopia, Nigeria and other parts of West Africa estimate the incidence of OF to be 1-10 per 1000 births [40]. Unless they have access to a hospital that provides subsidized treatment and care, women may live with the fistula until they die, often at a very young age, from complications of their fistula [43]. such women often receive no support from their husbands or family members. At the Addis Ababa Fistula Hospital, 53\% of the women had been abandoned by their husbands, and one woman in every five said that she had to beg for food to survive [43]. In India and Pakistan, some $70 \%$ to $90 \%$ of women with fistula had been abandoned or divorced, according to limited hospital studies [42]. It is not surprising, therefore, that some women can no longer cope with the pain and suffering, and resort to suicide [41].

Facility-based studies are limited to women who access the facility. Women who do not access facilities are excluded from these studies [44. This study seeks to identify the social features and morbidity patterns of obstetric fistula in women at the obstetric fistula center in, Bingham University Teaching Hospital, Jos, Plateau State, Nigeria.

\section{MAterials AND MethodS}

The study was conducted in the Fistula Centre of Bingham University Teaching Hospital (BHUTH), Jos in 2019. It is located within BHUTH premises in Jos North local Government of Plateau State. It is a 20-bed centre where patients stay for an average of 8-20 days in the ward receiving treatment. After discharge, patients have an option of staying in the VVF hostel or going home. The bed occupancy in the hostel ranges from 30-90 days varying with different times of the year. Patients that stay in the hostel are cared for by their relatives. A Matron oversees the management of the ward and the hostel.

The was a descriptive study that involved all obstetric fistula patients in the ward and those in the VVF hostel who gave consent to participate in the study. The Centre receives patients from every part of Nigeria and conducts about 450 fistula surgeries in a year. The Fistula Centre also offers physiotherapy, psychological counselling, health and nutrition classes, a post-surgery skill acquisition program, extensive community outreach and patient screening/identification. The VVF Centre runs a weekly outpatient clinic on Tuesdays for new clients and another clinic on Fridays to review patients on the ward. Surgeries are done twice in a week (Thursdays and Fridays). The Centre is funded by organizations mostly from the United States of America. The Centre is managed by a Project Director who is a Fistula Surgeon.

An Interviewer-administered structured questionnaire was used to collect relevant information from all women affected by OF at the Centre. Questionnaire looked at social and health aspects of obstetric fistula in all 49 patients at the center. Data was analyzed using a computer software; Statistical Package for the Social Science (SPSS) version 20.0. Descriptive statistics, proportions, tables, and diagrams were generated to illustrate findings. Data is based on recall information; therefore, it is open to bias. The anticipated language barrier was mitigated using interpreters and research assistants who were proficient in the local language. Ethical approval for the study was given by the Bingham University Teaching Hospital Ethical Committee. patients gave informed consent for questionnaires to be administered.

\section{RESULTS}

\section{A. Marital Status, Ethnic Group, Antenatal Attendance of Respondents}

In Table I, most respondents were $28(57.1 \%)$ married in a monogamous setting before fistula developed, 15 (30.6\%) were married in a polygamous setting. On the other hand, $12.2 \%$ of patients were single. Most respondents $10(20.0 \%)$ of the women with obstetric fistula were Hausa followed by Fulani (18\%), Mumuye (8.2\%), Eggon and Tangale (6.1\%), Tiv, Tarok, Kanuri and Bajju (4.1\% each).

Majority 39 (79.6\%) of the patients attended ANC during their last pregnancy whereas $10(20.4 \%)$ did not. A higher proportion $19(38.8 \%)$ of patients had 4-6 ante-natal care visits, $13(26.5 \%)$ had 1-3 ante-natal care visits, while 6 (12.2\%) had 7-9 visits. Most women 18 (36.7\%) had their antenatal care in a General Hospital, $18(36.7 \%)$ in PHC and $3(6.1 \%)$ Private Clinics.

TABLE I: MARITAL STATUS, ETHNIC GROUP, ANTENATAL FEATURES OF RESPONDENTS

\begin{tabular}{|c|c|c|}
\hline $\begin{array}{c}\text { Marital status before fistula } \\
\text { developed }\end{array}$ & $\begin{array}{c}\text { No of Fistula } \\
\text { Patients }\end{array}$ & Percent \\
\hline Married in Monogamous Setting & 28 & 57.1 \\
\hline Married in a Polygamous Setting & 15 & 30.6 \\
\hline Single & 6 & 12.2 \\
\hline Ethnic Group & $\begin{array}{c}\text { No. of fistula } \\
\text { patients }\end{array}$ & Percent \\
\hline Hausa & 10 & 20.4 \\
\hline Fulani & 8 & 16.3 \\
\hline Mumuye & 4 & 8.2 \\
\hline Eggon & 3 & 6.1 \\
\hline Tangale & 3 & 6.1 \\
\hline Bajju & 2 & 4.1 \\
\hline Kanuri & 2 & 4.1 \\
\hline Tarok & 2 & 4.1 \\
\hline Tiv & 2 & 4.1 \\
\hline Others* & $* 13$ & $* 26.5$ \\
\hline ANC Attendance Status & $\begin{array}{l}\text { No. of fistula } \\
\text { patients }\end{array}$ & Percent \\
\hline Attended & 39 & 79.6 \\
\hline Did Not Attend & 10 & 20.4 \\
\hline Place Of ANC & $\begin{array}{c}\text { No of Fistula } \\
\text { Patients }\end{array}$ & Percent \\
\hline Did Not Attend & 10 & 20.4 \\
\hline General Hospital & 18 & 36.7 \\
\hline $\mathrm{PHC}$ & 18 & 36.7 \\
\hline Private Clinics & 3 & 6.1 \\
\hline Number of ANC Visits & $\begin{array}{c}\text { No of Fistula } \\
\text { Patients }\end{array}$ & Percent \\
\hline None & 10 & 20.4 \\
\hline $1-3$ & 13 & 26.5 \\
\hline $4-6$ & 19 & 38.8 \\
\hline $7-9$ & 6 & 12.2 \\
\hline$>10$ & 1 & 2.0 \\
\hline Total & 49 & 100.0 \\
\hline
\end{tabular}

*Other ethnic groups which includes: Afor, Balanga, Bashambe, Chobo, Duma, Jamawa, Jukun, Kilba, Kon, Otep, Waja, Yola, Zimm contributed 2\% (1 fistula patient) each. 


\section{B. Financial Support and Source of Financial Support among Respondents}

Table II shows that $34(69.4 \%)$ of patients had some form of financial support while $15(30.6 \%)$ had no form of financial support.

Table II revealed that $21(42.9 \%)$ of the respondents' received financial support from family members, 19 (38.8\%) of the respondents received financial support from their Husbands, $18.4 \%$ of the respondents received financial support from their parents, while only $2 \%$ of the respondents received financial support from their friends. Majority were $45(91.8 \%)$ out of pocket, only $4(8.2 \%)$ were via health insurance.

\begin{tabular}{lcc}
$\begin{array}{c}\text { TABLE II: FINANCIAL SUPPORT AND SOURCE OF FINANCIAL SUPPORT } \\
\text { AMONG RESPONDENTS }\end{array}$ & $\begin{array}{c}\text { No of Fistula } \\
\text { Patients }\end{array}$ \\
& & Percent \\
\hline $\begin{array}{c}\text { Financial Support } \\
\text { Yes }\end{array}$ & 34 & 69.4 \\
No & 15 & 30.6 \\
Total & 49 & 100.0 \\
Source of Financial support & & \\
Family & 21 & 42.9 \\
Husband & 19 & 38.8 \\
Parent & 9 & 18.4 \\
Charity & 5 & 10.2 \\
Friends & 1 & 2.0 \\
Total & 49 & 100.0 \\
Type of funding & & 91.8 \\
Out of pocket & 45 & 8.2 \\
Health Insurance & 4 & 100.0 \\
Total & 49 &
\end{tabular}

\section{Social and Sexual Features of Obstetric Fistula on Respondents}

In Table III, most 28 (57.1\%) of the women reported that their relationship with spouse was affected by Obstetric Fistula while $21(42.9 \%)$ reported that their relationship was not affected. Of those impacted by obstetric fistula, 19 $(67.9 \%)$ were separated, $8(28.6 \%)$ had the relationship strained, $1(3.6 \%)$ had no financial support afterwards. Obstetric fistula affected Sexual Intercourse in $26(53.1 \%)$ of the women while in $23(46.9 \%)$ of the women Sexual Intercourse was unaffected.

Majority $33(67.3 \%)$ of the women owned a room to themselves while 16 (32.7\%) of the women did not.

A higher proportion 37 (75.5\%) of the women did not work or did not do any businesses while only 12 (24.5\%) of the women worked or engaged in businesses.

On effect on their families Also in $9(18.4 \%)$ of patients, their relationship affected, while $40(81.6 \%)$ were not affected. Of those affected, some were separated $2(22.2 \%)$, not financed $4(44.4 \%)$, avoided $3(33.3 \%)$

\section{Community Organization, Community Acceptance,} History and Number of Fistula Repair

In Table IV, a higher proportion $28(57.1 \%)$ of the women were members of a community organization while 21 $(42.9 \%)$ did not belong to any community organization despite their situation.

Majority 34 (69.4\%) of the women remain accepted in their community while $15(30.6 \%)$ of the women did not get acceptance in their community.
Majority $33(67.3 \%)$ of the women have had fistula repair while $16(32.7 \%)$ of the women have had no fistula repair. Of those who have had previous repairs, 14 (28.6\%) women have had fistula repaired once, $4(8.2 \%)$ have had fistula repairs twice, $6(12.2 \%)$ women have had repair done three times, while $3(6.1 \%)$ women each had fistula repaired done 4 and 5 times, respectively.

TABLE III: SOCIAL AND SEXUAL FEATURES OF OBSTETRIC FISTULA ON RESPONDENTS

\begin{tabular}{|c|c|c|}
\hline & $\begin{array}{c}\text { No of fistula } \\
\text { patients }\end{array}$ & $\begin{array}{c}\text { Perce } \\
\text { nt }\end{array}$ \\
\hline \multicolumn{3}{|l|}{ Impact of OF on Relationship with partner } \\
\hline Relationship Affected & 28 & 57.1 \\
\hline Relationship Not Affected & 21 & 42.9 \\
\hline Total & 49 & 100.0 \\
\hline \multicolumn{3}{|l|}{ Effect of OF on relationship with spouse } \\
\hline Separation & 19 & 67.9 \\
\hline Strained Relationship & 8 & 28.6 \\
\hline No Financial Support & 1 & 3.6 \\
\hline Total & 28 & 100.0 \\
\hline \multicolumn{3}{|l|}{ Impact on Sexual Intercourse } \\
\hline Sexual Intercourse Affected & 26 & 53.1 \\
\hline Sexual Intercourse Not Affected & 23 & 46.9 \\
\hline Total & 49 & 100.0 \\
\hline \multicolumn{3}{|l|}{ Possession of Room to Yourself } \\
\hline Possessed A Personal Room & 33 & 67.3 \\
\hline Did Not Possess a Personal Room & 16 & 32.7 \\
\hline Total & 49 & 100.0 \\
\hline \multicolumn{3}{|l|}{ Impact OF on Relationship with family } \\
\hline Relationship Affected & 9 & 18.4 \\
\hline Relationship Not Affected & 40 & 81.6 \\
\hline Total & 49 & 100.0 \\
\hline \multicolumn{3}{|l|}{ Effect of OF on relationship with family } \\
\hline No Financial Support & 4 & 44.4 \\
\hline Avoided & 3 & 33.3 \\
\hline Separation & 2 & 22.2 \\
\hline Total & 9 & 100.0 \\
\hline \multicolumn{3}{|l|}{ Possession of business or work } \\
\hline Possessed a business/work & 12 & 24.5 \\
\hline Did not possess a business/work & 37 & 75.5 \\
\hline Total & 49 & 100.0 \\
\hline
\end{tabular}

TABLE IV: COMMUNITY ORGANIZATION, COMMUNITY ACCEPTANCE, PAST HISTORY AND NUMBER OF FISTULA REPAIR

\begin{tabular}{lcc}
\hline & $\begin{array}{c}\text { No of fistula } \\
\text { patients }\end{array}$ & Percent \\
\hline $\begin{array}{l}\text { Membership of Community Organization } \\
\text { Belonged to a community }\end{array}$ & 28 & \\
organization & & 57.1 \\
Did not belong to a community & 21 & 42.9 \\
organization & 49 & 100.0 \\
Total & & \\
Acceptance in the Community & 34 & 69.4 \\
Accepted in the community & 15 & 30.6 \\
Rejected in the community & 49 & 100.0 \\
Total & & \\
Fistula Repair in the past & 33 & 67.3 \\
Had a Fistula repair in the past & 16 & 32.7 \\
Had no Fistula repair & 49 & 100.0 \\
Total & & \\
Number of fistula repair & 16 & 32.7 \\
0 & 14 & 28.6 \\
1 & 4 & 8.2 \\
2 & 6 & 12.2 \\
3 & 3 & 6.1 \\
4 & 3 & 6.1 \\
5 & 1 & 2.0 \\
6 & 1 & 2.0 \\
7 & 1 & 2.0 \\
8 & 49 & \\
Total & & \\
& & \\
& &
\end{tabular}




\section{E. Surgical Concerns, Outcomes, Childbirth and Number} of Childbirth Post-surgery, Reasons not Being Able to Get Pregnant after Repair

A higher proportion $40(81.6 \%)$ of the women had no concern before the surgery while $9(18.4 \%)$ had concerns before the repair. Their concerns included 7 (14.3\%) fear that the Fistula was irreparable, $4(8.2 \%)$ concern about difficulty in conceiving after the surgery, $3(6.1 \%)$ feared death during surgery, while $2(4.1 \%)$ of the respondents felt they would not be able to get married again.

On surgical outcome, $8(16.3 \%)$ were completed dry and leaking had ceased, $18(36.7 \%)$ of the women were still leaking urine after the surgery. Eight (16.3\%) just had surgery while $15(30.6 \%)$ were waiting to have their surgeries done.

Almost all 48 (98\%) of the women have had no childbirth after the repair, while $1(2 \%)$ have had childbirth after the surgical repair. Reasons for inability to get pregnant include $21(42.9 \%)$ still on admission, $11(22.4 \%)$ unknown reason, $7(14.3 \%)$ are divorced, $6(12.2 \%)$ separated from husband, 2 $(4.1 \%)$ are still breastfeeding, $1(2.0 \%)$ have completed family cycle.

TABLE V: SURGICAL CONCERNS, OUTCOMES, CHILDBIRTH AND NUMBER OF CHILDBIRTH POST-SURGERY, REASONS NOT BEING ABLE TO GET

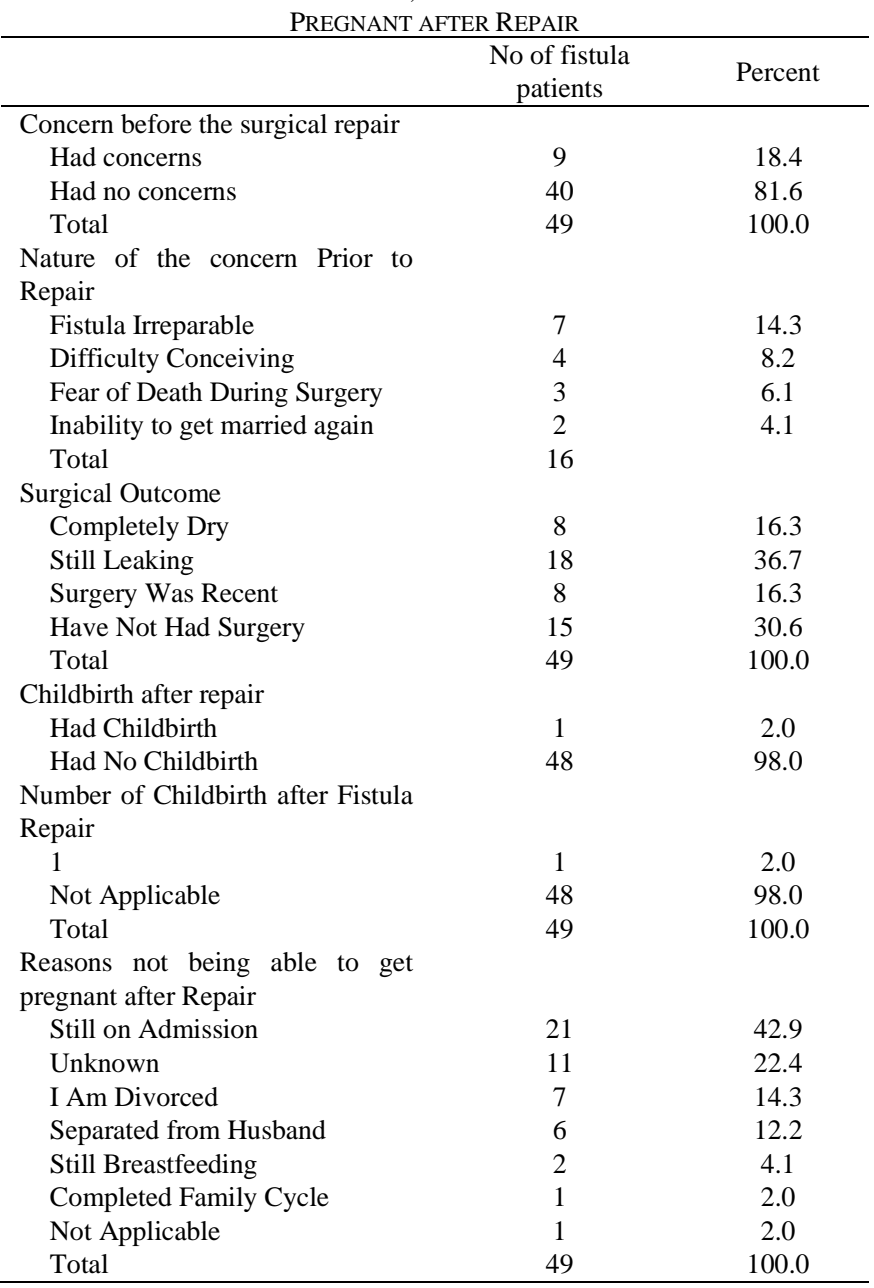

\section{F. Morbidity Features of Obstetric Fistula among Respondents}

Concerning morbidity features of obstetric fistula among respondents, they had mental health issues like the prevalence of depressive mood was $37(75.5 \%)$ among the respondents, anxiety 27 (55.1\%), Headache 19 (38.8\%), fatigue 17 (34.7\%). Participants also had gynaecological morbidities like vulval dermatitis 13 (26.5\%), irregular menstrual flow 13 (26.5\%), abnormal vaginal discharge $12(24.5 \%)$, dysuria 11 $(22.4 \%)$ and suicidal ideation $10.2 \%$. The women also had lower abdominal pain $30(61.2 \%)$, loss of weight $24(49.0 \%)$, backache $22(44.9 \%)$ and foot drop 20 (40.8\%).

Majority, $35(71.4 \%)$ indicated that the child did not survive after the pregnancy that led to the obstetric fistula while $14(28.6 \%)$ respondents revealed that the child survived after delivery.

TABLE VI: MORBIDITY FEATURES OF OBSTETRIC FISTULA AMONG

\begin{tabular}{ccc} 
& RESPONDENTS & \\
\hline *Health Consequences & $\begin{array}{c}\text { No of Fistula } \\
\text { Patients }\end{array}$ & Percent $(\%)$ \\
\hline Depressive mood & 37 & 75.5 \\
Lower Abdominal Pain & 30 & 61.2 \\
Anxiety & 27 & 55.1 \\
Loss of Weight & 24 & 49.0 \\
Backache & 22 & 44.9 \\
Foot Drop & 20 & 40.8 \\
Headache & 19 & 38.8 \\
Fatigue & 17 & 34.7 \\
Vulva dermatitis & 13 & 26.5 \\
Irregular Menstrual Flow & 13 & 26.5 \\
Abnormal Vaginal & 12 & 24.5 \\
Discharge & 11 & 24.4 \\
Dysuria & 11 & 22.4 \\
Dizziness & 5 & 10.2 \\
Suicidal Ideation & No of Fistula & Percent \\
Child Survival of & Patients & 28.6 \\
pregnancy leading to OF & 14 & 71.4 \\
Yes & 35 & 100.0 \\
No & 49 & \\
Total & & \\
* Multiple response & & \\
\hline
\end{tabular}

\section{DISCUSSION}

Studies done in Kano [45], Jos [46] and Port Harcourt [47] have shown the relevance of marriage and ethnicity in the occurrence of Obstetric fistula. In this study, half of the respondents were married in a monogamous setting before fistula developed, a third married in a polygamous setting and just a few of the patients were single. In terms of origin, most respondents $(20.0 \%)$ were Hausa and Fulani $(18 \%)$ others were Mumuye, Eggon and Tangale, Tiv, Tarok, Kanuri and Bajju. These ethnic groups are domiciled in Northern Nigeria where early marriage and prolonged labour are still prevalent. The is a need for a collective reorientation of communities in across the country to reduce the burden of obstetric fistula especially among northern states.

It is a good sign that majority of the patients attended ANC during their last pregnancy while just a few did not. And of these a higher proportion of patients had 4 to 6 ante-natal care visits, and these visits were in health facilities with skilled birth attendants. Now the question is why did these same patients end up with obstetric fistulae? This is attributable to the fact that despite attending antenatal classes, patients still prefer to deliver at home and rush to hospital only when the labour is prolonged. The fact that these women attended antenatal classes is a huge opportunity for the public health system to educate women on the danger signs of pregnancy and consequences of delays in accessing skilled care and emergency obstetric care. In contrast, studies done in 
Northwest Nigeria had only $42 \%$ attending ANC. Thus, this is an improvement in ANC attendance is commendable.

The importance of health care funding in access to quality health care is currently in the front burner in public health conversations, in this study, $69.4 \%$ of patients had some form of financial support while a third $30.6 \%$ had no form of financial support. This financial support was $92 \%$ out of pocket, as only a few had health insurance. This is similar to finding in the National Demographic and Health Survey [48] where only $3 \%$ had health insurance. There is need to increase this number to achieve Universal Health Coverage. This study also reveals that family members are useful contributor's and supporters to the health challenges of family members as about half of the respondents' received financial support from family members, similarly, husbands have been useful supporter of their spouses and partners as revealed in this study where more than a third of the respondents received financial support from their husbands, parents and friends were also helpful in fund raising. This fully exposes the relevance of family, husband, and friends in the health challenges of women. Thus, targeted activities can be done to support this essential base of women in need.

Generally, the social life and aspirations of women with obstetric fistula is affected by the condition itself. A lot of things change some of which lead to devastating consequences in the social health of affected individuals. Most women reported that their relationship with their spouse was affected by Obstetric Fistula. Obstetric fistula directly led to separation from their husband, strained relationship with their spouse, and loss of financial support afterwards. These social losses impact hugely on the lives of these women as their spouses flee from them due to apparent smell, infection, and lack of attraction due to the leakage of urine and the smells that occur. The gravity of the situation is reflected by the fact that obstetric fistula affected sexual intercourse in more than half of the women even though more than two third of the women owned a room to themselves. This situation is a huge challenge on the sexual and reproductive health of these women. It tends to lead to depression, anxiety, and suicidal ideation. It affects the social and societal confidence these women have. Looking at the employment and income status of these women, three quarters of these women did not work or did not do any businesses while only quarter worked or engaged in a business. This gives an overall idea of the social status of women suffering from this disease. It is found mainly among the poor, unemployed and less educated. This is reiterated in studies done in Benin [49], Jos [46], and in a multicenter study done in Kano, Katsina, Sokoto and Kaduna (Laure fistula center, Bubbara ruga fistula center, Maryam Abacha Women \& children hospital, and Gambo Sawaba General Hospital) [50]. It is interesting to note the strong support from family members for patients in this situation, as only a few patients had the obstetric fistula condition affect their relationship as $82 \%$ were not affected. But those affected, $22 \%$ were separated, $44 \%$ lost financing, $33 \%$ were avoided.

The relevance of the community in the social health of respondent was highlighted as a higher proportion of the women were members of a community organization despite their situation. And this membership is an outward demonstration of social and communal integration of these women in their communities. Despite their socially disadvantageous situation, more than two thirds of the women remain accepted in their community while a third was not accepted. This trend is encouraging but, efforts should be made to cater for those who have lost their community integration. The reoccurrence of the condition is reflected in repeated surgical repairs, majority $(67.3 \%)$ of the women have had fistula repair, of those who have had previous repairs, a few have had fistula repaired once, twice, ad repair done three times, 4 and 5 times, respectively. This is similar to findings done in Benin [49], as they reviewed the psychosocial problems of patients with vesico-vaginal fistula.

The preparation for surgery is commonly filled with anxiety and concerns among patients. The women expressed a great deal of confidence in the surgical system as almost all the women had no concern before the surgery. But about $20 \%$ had concerns before the surgical repair. Their concerns included that the Fistula was irreparable, concern about difficulty in conceiving after the surgery, death during surgery, and getting married after the surgery.

A thrilling part surgical intervention is the outcome, in this regard, $16 \%$ were completed dry and leaking had ceased post operatively, but sadly, $37 \%$ of the women were still leaking urine after the surgery. This in contrast to finding done in western Uganda ${ }^{10}$ where $77.9 \%$ had successful closure of their fistula. This difference could be due to patient factors like size of fistula, comorbidities; surgeons' factors like skill, surgical technique, facilities, postoperative management and other variables which are difficult to compare [47]. Overall success rates of vesicovaginal fistula repair were $75 \% 91.5 \%$, $92 \%$, and $87.9 \%$ in Port Harcourt [47], Ile-Ife [51], Jos [46] and Ilorin [52], respectively. A typical sign of wellness is restoration of ability to achieve pregnancy after treatment of obstetric fistula, almost all the women have had no childbirth after the surgical repair of obstetric fistula. Women stated that reasons for inability to get pregnant to include still being on admission, unknown reason, divorced, separated from husband, still breastfeeding, and have completed family cycle. Similarly, women who have had fistula find it difficult to conceive because of multifactorial causes like which could be psychological, lack of sexual drive or due to stenosis of the vagina.

Numerous researchers will worry about the health aftermath of obstetric fistula patient and try to delineate the morbidity pattern among this special group of people. It is keenly observed that most patients had mental health issues typified by the high prevalence of depressive mood, anxiety, headache, and fatigue. Due to the anatomical location of obstetric fistula, women had lower abdominal pain, weight loss, backache, and foot drop. It is significant to note that majority of the children did not survive after the pregnancy that led to the obstetric fistula. This is due to leakage of urine and the infective process that affects the area. Participants also had gynaecological morbidities like vulval dermatitis (27\%), irregular menstrual flow, abnormal vaginal discharge (25\%), dysuria (22\%) and suicidal ideation (10\%). This was also reported in studies done in Kano [45], Benin [23]. This presents another health burden to the women in this category. The battle against OF must be done alongside management of the other health challenges. These morbidities affect the sexual and reproductive life of the women. 


\section{CONCLUSION}

Most respondents were married in a monogamous setting before fistula developed. Most respondents with obstetric fistula were Hausa followed by Fulani. Majority of the patients attended ANC during their last pregnancy and a higher proportion of patients had 4-6 ante-natal care visits and most women had their antenatal care in health facility. Most of patients had some form of financial support especially from family members, husbands, parents, and friends.

Most of the women had their relationship affected, majority were separated, and relationship strained, loss of financial support from their spouse. Sexual Intercourse was also affected. A higher proportion of the women did not work or did not do any businesses and had been separated from family, lost finance, and avoided. Majority of the women were members of community organizations and remain accepted in their community. Most of the women have had fistula repair in the past.

A higher proportion of the women had no concern before the surgery. Their concerns included fear that the Fistula was irreparable, concern about difficulty in conceiving after the surgery, some feared death during surgery and others felt they will be unable to get married again. On surgical outcome, $16 \%$ became completely dry and leaking had ceased, a third was still leaking urine after the surgery. Almost all the women had no childbirth after the repair. Women had mental health issues like depression, anxiety, headache, and fatigue. Participants also had gynaecological morbidities like vulval dermatitis, irregular menstrual flow, abnormal vaginal discharge, dysuria, and suicidal ideation. The women also had lower abdominal pain, loss of weight, backache, and foot drop. Majority of the children did not survive after the pregnancy that led to the obstetric fistula.

\section{RECOMMENDATION}

\section{A. To the Women, Husbands, Family, and Community Members of Patients with Obstetric Fistula}

Women should leverage on financial support from family member to avoid delays in seeking help during pregnancy. Families are encouraged to continue to give physical, mental, and social support to women with obstetric fistula. Husbands are requested to show empathy to their spouses who suffer from obstetric fistula. They should cater for the needs of the women. Communities are encouraged to continue to give moral, emotional, financial, and social support to fistula patients. They should discourage neglect, separation of obstetric fistula patients.

\section{B. To the Healthcare Facilities and Workers}

Healthcare workers should in addition to other services, also focus on management of gynaecological morbidities, mental health issues and other complications associated with obstetric fistula.

\section{To the Government}

Government can initiate poverty alleviation activities and help reduce out of pocket expenses for healthcare via health insurance. The creation of jobs for women will help empower women to seek healthcare just in case the spouse and family members are unable to support.

\section{REFERENCES}

[1] World Health Organization, Maternal Mortality in 2000: Estimates developed by WHO, UNICEF and UNFPA, Geneva, World Health Organization, 2003,23-27, www.who.int/reproductive-health/ publications.

[2] Stanton C, Holtz SA, Ahmed S. Challenges in measuring obstetric fistula. Int J Gynaecol Obstet. 2007;99 Suppl 1:S4-9. doi: http://dx.doi.org/10.1016/j. ijgo.2007.06.010 PMID: 17765240.

[3] Federal Ministry of Health, Standard of Practice on Obstetric fistula in Nigeria, December 2011, Chapter 2\&3, pp 9-15. http://www.health.gov.ng/doc/DOCTOR'S\%20VERSION\%201.pdf.

[4] Muleta M, Rasmussen S, Kiserud T. Obstetric fistula in 14,928 ethiopian women. Acta Obstet Gynecol Scand. 2010;89 (7):945-951. doi:10.3109/00016341003801698.

[5] WHO, Ten facts on obstetric fistula. World Health Organization. 2018 [cited 12 December 2018]. 11-12. Available from: https://www.who.int/features/factfiles/obstetric_fistula/en/.

[6] Baker Z, Bellows B, Bach R, Warren C. Barriers to obstetric fistula treatment in low-income countries: a systematic review. Trop Med Int Heal. 2017;22(8):938-959. doi:10.1111/tmi.12893.

[7] Kzaura M R Kamazima R S Mangi E J. Perceived causes of obstetric fistulae from rural southern Tanzania. Afr Health Sci. 2011;11(3):377382.

[8] Umoiyoho AJ, Inyang-Etoh EC, Etukumana EA. Obstetric fistula repair: experience with hospital-based outreach approach in Nigeria. Glob J Health Sci. 2012;4(5):40-45. doi:10.5539/gjhs.v4n5p40.

[9] World Bank Development Report 2012. Nigeria Births Attended By Skilled Health Staff Percent Of Total [Internet]. Tradingeconomics.com. 2018 [cited 14 December 2018]. Available from: https://tradingeconomics.com/nigeria/births-attended-byskilled-health.

[10] Kayondo M, Wasswa S, Kabakyenga J, et al. Predictors and outcome of surgical repair of obstetric fistula at a regional referral hospital, Mbarara, western Uganda. BMC Urol. 2011;11. doi:10.1186/14712490-11-23.

[11] USAID. 2016. Repairing Obstetric Fistula in Nigeria. 23- 25 https://wwwusaidgov/sites/default/files/success/files/fp_nga_fistulapd f (Accessed Nov 2018).

[12] Browning A, Menber B. Women with obstetric fistula in Ethiopia: A 6-month follow up after surgical treatment. BJOG An Int J Obstet Gynaecol. 2008;115(12):1564-1569. doi:10.1111/j.14710528.2008.01900.x.

[13] Donnay F, Weil L. Obstetric fistula: The international response. Lancet. 2004;363(9402):71-72. doi:10.1016/S0140-6736(03)15177-X

[14] Ijaiya MA, Rahman A G, Aboyeji A P, Olatinwo AW, Esuga S A, Ogah O K, Raji H O, Adebara I O, Akintobi AO, Adeniran AS, Adewole A A. Vesicovaginal Fistula: A Review of Nigerian Experience Vesicovaginal Fistula : A Review of Nigerian Experience. West Afr J Med. 2010;29(5):294-299. doi:10.4314/wajm.v29i5.68247.

[15] Wall L L Arrowsmith S D Briggs ND Lassey A. Urinary Incontinence in the Developing World: The Obstetric Fistula.; 1996:45- 48.

[16] Sjøveian S, Vangen S, Mukwege D, Onsrud M. Surgical outcome of obstetric fistula: A retrospective analysis of 595 patients. Acta Obstet Gynecol Scand. 2011;90(7):753-760. doi:10.1111/j.16000412.2011.01162.x.

[17] Donnay F, Ramsey K. 2006. "Eliminating Obstetric Fistula: Progress in Partnerships." International Journal of Gynecology and Obstetrics 94 (3): 256-61.

[18] Gebresilase YT. A qualitative study of the experience of obstetric fistula survivors in Addis Ababa, Ethiopia. Int $\mathrm{J}$ Womens Health. 2014;6:1033-1043. doi:10.2147/IJWH.S68382.

[19] Njoku CO, Njoku AN. Obstetric Fistula: The Agony of Unsafe Motherhood. A Review of Nigeria Experience. J Adv Med Med Res. 2019;28(12):1-7. doi:10.9734/jammr/2018/v28i1230040.

[20] Maulet N, Keita M, Macq J. Medico-social pathways of obstetric fistula patients in Mali and Niger: An 18-month cohort follow-up. Trop Med Int Heal. 2013;18(5):524-533. doi:10.1111/tmi.12086.

[21] Adler AJ, Ronsmans C, Calvert C, Filippi V. Estimating the prevalence of obstetric fistula: A systematic review and meta-analysis. BMC Pregnancy Childbirth. 2013;13. doi:10.1186/1471-2393-13-246.

[22] Kabir, M, Iliyasu Z, Abubakar I S and Umar U I, Medico-social Problems of women with Vesico-Vagina Fistula in Murtala Mohammed Specialist Hospital, Kano. Annals of African Medicine. Vol. 2, No. 2; 2003: pp. 54-57.

[23] Gharoro, E., \& Agholor, K. (2009). Aspects of psychosocial problems of patients with vesico-vaginal fistula. Retrieved from https://www.tandfonline.com/doi/abs/10.1080/01443610903100609.

[24] Khisa Weston Stephen Mutiso Judy W. Mwangi, Demographic and Medical Profile of patients with Obstetric fistula in Kenyatta National 
Hospital, Kenya. International Journal of Obstetric Trauma. Vol 1 No1. ISSN: 2046-4665.

[25] Olusegun A, Akinfolarin A, Olabisi L. A Review of Clinical Pattern and Outcome of Vesicovaginal Fistula. Journal of the National Medical Association. 2009;101(6):593-595.

[26] Anzaku, S., Lengmang, S., Mikah, S., Shephard, S., \& Edem, B. (2016). Sexual activity among Nigerian women following successful obstetric fistula repair.

[27] Dereje M, Woldeamanuel Y, Asrat D, Ayenachew F. Urinary tract infection among fistula patients admitted at Hamlin fistula hospital, Addis Ababa, Ethiopia. BMC Infectious Diseases. 2017;17(1).

[28] Zeleke, B., Ayele, T., Woldetsadik, M., Bisetegn, T., \& Adane, A. (2019). Depression among women with obstetric fistula, and pelvic organ prolapse in Northwest Ethiopia.

[29] Muleta, M., Hamlin, C., Fantahun, M, Kennedy, R., \& Tafesse, B. (2008). Health and Social Problems Encoun- tered by Treated and Untreated Obstetric Fistula Patients in Rural Ethiopia, Addis Ababa Fistula Hospital, Addis Ababa, Ethiopia, J Obstet Gynaecol, 30(1): 4450.

[30] Debrework T B, Abebaw G W and Mezgebu Y M, Consequences of obstetric fistula in sub-Sahara African countries, from patients' perspective: a systematic review of qualitative studies. Published 20th June 2018. BMC Wome.23.

[31] UNFPA, Women's dignitary project about Fistula;[Internet] Living with Obstetric fistula: The devastating effects of the condition and ways of coping. Engender Health and UNFPA. [Cited 28th March 2019] Available here: https://www.engenderhealth.org/files/pubs.

[32] Muleta M \& William G. Postcoital Injuries at the Addis Ababa Fistula Hospital, 1991-1997. Lancet 1999; 354(9195):2051.

[33] Holme A, Breen M \& MacArthur C (2007). Obstetric fistulae: a study of women managed at the Monze Mission Hospital, Zambia. British Journal of Obstetrics and Gynaecology 2007; 114(8): 1010-1017.

[34] David Nwoba Nweke,Monday Nwite Igwe, Psychosocial Experiences of subjects with VVF, A Qualitative Study. Global Journal of Medicine and Public health 2017,: 6( 1) 25-29 .[Cited 30th March 2019] Available here: http://www.gjmedph.com/uploads/O5-Vo6No1.

[35] Ibrahim T, Sadig AU and Daniel SO. Characteristics of vesicovaginal patients as seen at the specialist hospital in Sokoto; Nigeria. West African Journal of Medicine 2000; 19: 59-63.

[36] Diallo M. Social immersion strategy for reintegration and empowerment of obstetric fistula survivors. International Journal of Gynecology and Obstetrics 2009; 107 (Suppl 2): S93-S39.

[37] Kimani MZ, Omondi O, and, Anthony K. The prevalence and impact of obstetric fistula on women of Kaptembwa Nakuru, Kenya. International Journal of Applied Science and Technology 2014; 4 (273).

[38] Ahmed S, Holtz S A; Social and economic consequences of obstetric fistula: Life changed forever? International Journal of Gynecology and Obstetrics (2007)99, 510-515. doi:10.1016/j.ijgo.2007.06.011 Available here: https://www.researchgate.net/publi.

[39] Gebresilase YT. A qualitative study of the experience of obstetric fistula survivors in Addis Ababa, Ethiopia. Int J Womens Health. 2014;6:1033-43.

[40] Zacharin RF. A history of obstetric vesicovaginal fistula. ANZ Journal of Surgery, 2000, 70:851-854.

[41] The World Health Report, 2005-Make every mother and child count, 2005, Geneva, World Health Organization, www.who.int/whr.
[42] WHO analysis of causes of maternal deaths: a systematic review. K.S. Khan and al. Lancet 2006; 367: 1066-1074.

[43] AbouZahr C. Global burden of maternal death. British Medical Bulletin. Pregnancy: Reducing maternal death and disability. British Council. Oxford University Press. 2003. pp.1-13. www.bmb.oupjournals.org.

[44] Tunçalp Ö, Tripathi V, Landry E, Stanton K, Ahmed S. Measuring the incidence and prevalence of obstetric fistula: approaches, needs and recommendations. Bull World Heal Organ. 2015;93(June 2014):60-62.

[45] Kabir M Iliyasu Z Abubakar S Umar U I. Medico-Social Problems Of Patients With Vesico- Vaginal Fistula In Murtala Mohammed Specialist Hospital, Kano. Ann Afr Med. 2003;2(2):54-57.

[46] Wall LL, Karshima AK, Kirschner C, Arrowsmith SD. The obstetric vesicovaginal fistula: Characteristics of 899 patents from Jos, Nigeria American Journal of Obstetrics and Gynaecology. 2004; 190: 10111019.

[47] Inimbga NM John CO Ekeke NO. Genitourinary Fistulae Experience in a University Teaching Hospital : A South-South Nigeria Perspective. Greener J Med Sci. 2018;8(1):5-10 doi:10.15580/GJMS.2018.1.010818003.

[48] Tukur I Ijiaya MA Su TT Chan K Muhammed Baba TA Karuthan C. Analysis of 137 Obstetric Fistula cases seen at Three Fistula Centers in Northwest Nigeria. East Afr Med J. 2015;92(8):408-414.

[49] Gharoro EP, Agholor KN. Aspects of psychosocial problems of patients with vesico- vaginal fistula. Journal of Obstetrics and Gynaecology 2009; 29:644-7.

[50] Ndugbu UK Madukwe CE Ezennia CJ. Why the Poor Care-Seeking Behavior forVesico- Vaginal Fistula Repair / Rehabilitation Care Among Patients Attending Vvf Centers in Northwestern. J Midwifery, Women's Heal Nurs Pract. 2019;(1):1-5.

[51] Orji E, Aduloju O, Orji V. Correlation and impact of obstetric fistula on motherhood. J Chinese Clin Med. 2007;2(8):448-454. http://nurse.9med.net/upload/200710261146574882.pdf.

[52] Ijaiya MA, Aboyeji AP, Ijaiya ZBB. Epidemiology of Vesico-Vaginal Fistula at the University of Ilorin Teaching Hospital, Ilorin, Nigeria. Trop J Obstet Gynaecol. 2002; 19: 101-103.

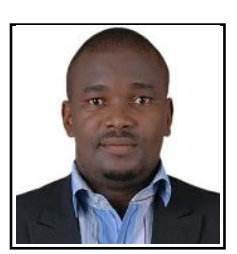

Okafor Kingsley Chinedu is a Consultant Community Health Physician and Epidemiologist. The has an MBBS degree with the University of Nigeria, he also has Master of Public Health (MPH), Master of Health Planning and Management (MHPM) and Master of Public Administration (MPA) all from University of Benin, Nigeria.

He is a Fellow of the West African College of Physicians (FWACP) in Community Health, and Fellow of the National Postgraduate Medical College (FMCPH) in Public Health and Community Medicine.

His research interest is in Epidemiology, Health Management, Adolescent and Reproductive Health and Occupational health.

Dr Okafor Kingsley Chinedu is a member of the Medical and Dental Consultants Association of Nigeria (MDCAN), Association of Public Health Physicians of Nigeria (APHPN), Epidemiology Society of Nigeria (EPISON), International Epidemiology Association (IEA), and the Nigerian Medical Association (NMA). 